\title{
Fibula autograft survival following resection of osteoclastoma of radius
}

\author{
M. L. H. LEE \\ M.A., M.B., F.R.C.S. \\ Consultant Orthopaedic Surgeon, \\ Bournemouth and East Dorset \\ Hospital Group
}

\author{
J. C. Sandeman \\ M.B., M.Ch.Orth., F.R.C.S.E., F.C.S.S.A., F.R.C.S. \\ Consultant Orthopaedic Surgeon and \\ Research Fellow, University of Liverpool
}

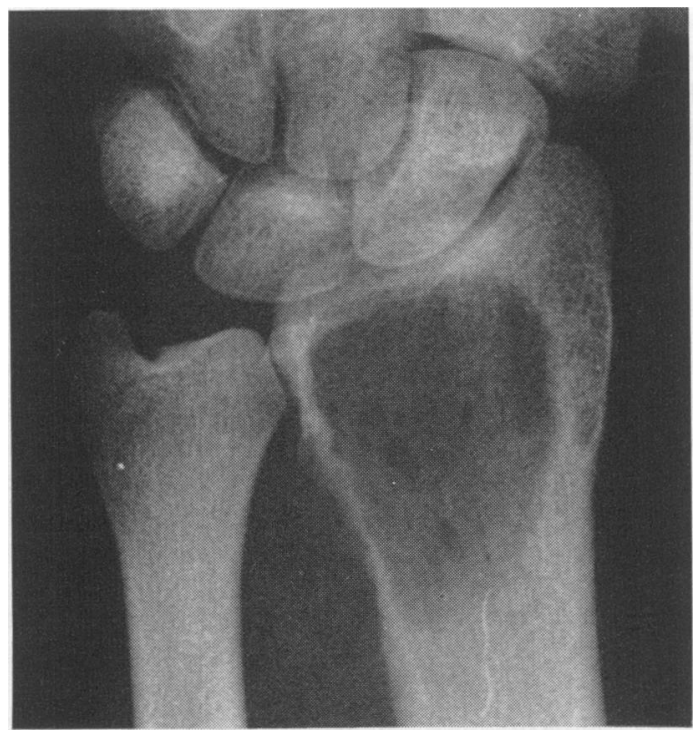

FIG. 1. Osteoclastoma lower end of the radius, 9 September 1965.

At operation, the proximal end of the right fibula was removed by sub-periosteal resection, step cuts made in the appropriate ends of the radius and fibula, and the fibula fixed as a forearm graft by two vitallium screws. The soft tissues of the wrist were not reconstructed, but the graft was transfixed to the carpus by a Kirschner wire. The graft was immobilized in an above-elbow plaster cast which was worn for 3 months.

On removal of the plaster, forearm and wrist alignment appeared normal, and X-ray in January 1966 (Fig. 3) showed incorporation of the graft which appeared of normal density and outline throughout its length.

After mobilization of the right arm for 1 week his elbow movements were $50-135^{\circ}$, and wrist extension $20^{\circ}$ and flexion $20^{\circ}$, but rotation was practically nil and with time this only achieved a total of $30^{\circ}$ whereas all other movements improved
Address for reprints: J. C. Sandeman, Department of Orthopaedic Surgery, University of Liverpool, Liverpool 3. 


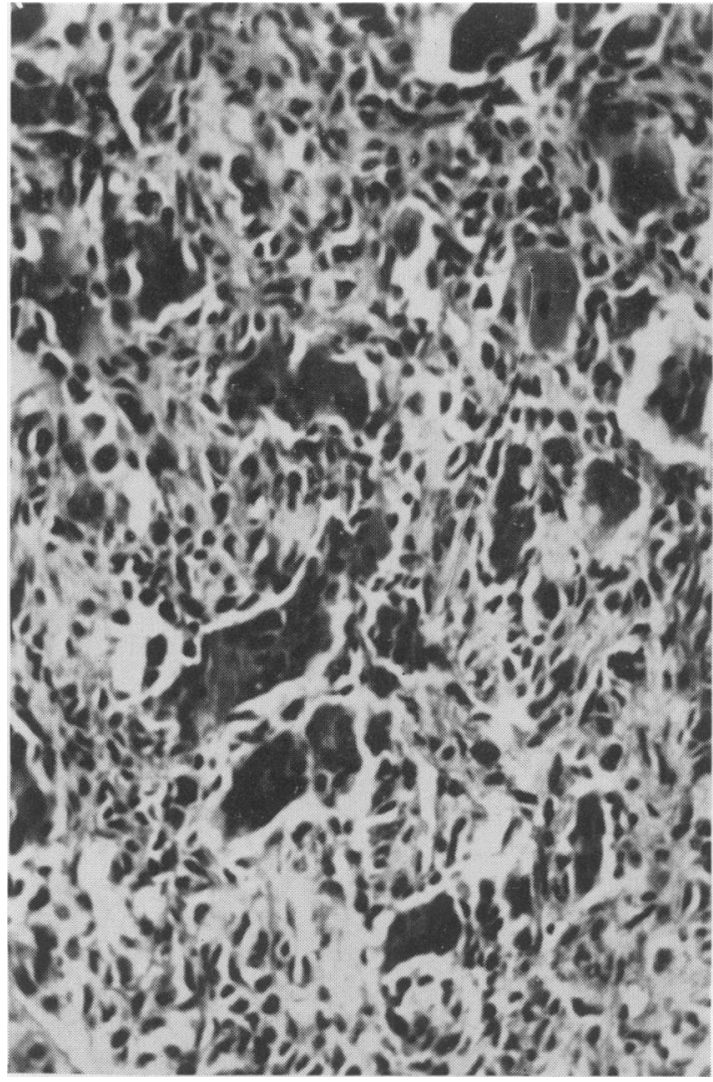

Fig. 2. Multi-nucleated giant cells and stroma of the osteoclastoma.

markedly. X-ray 4 months after the operation (Fig. 4) showed no recurrence of the tumour, and no change in the density or outline of the replacement graft. He already had a powerful grip and was able to work as a landscape gardener.

While playing soccer in December 1966, 14 months after the insertion of the graft, he sustained a blow on this wrist and fractured the graft in the area of the original tumour (Fig. 5). This was manipulated and placed in a forearm plaster cast, but the reduction was not maintained. Open reduction was performed through a dorso-lateral incision. The graft had a thick 'periosteum' which stripped off the bone with normal tension and left numerous small bleeding points. There was slight fibrosis in the old tumour area, but this was not a striking feature. The reduction was maintained by two transfixing Kirschner wires. An above-elbow plaster cast was applied.

In February 1967, 2 months after reduction of the fracture, there was clinical union with minimal deformity, and the forearm was left free. Three months later, however, it was noted that marked

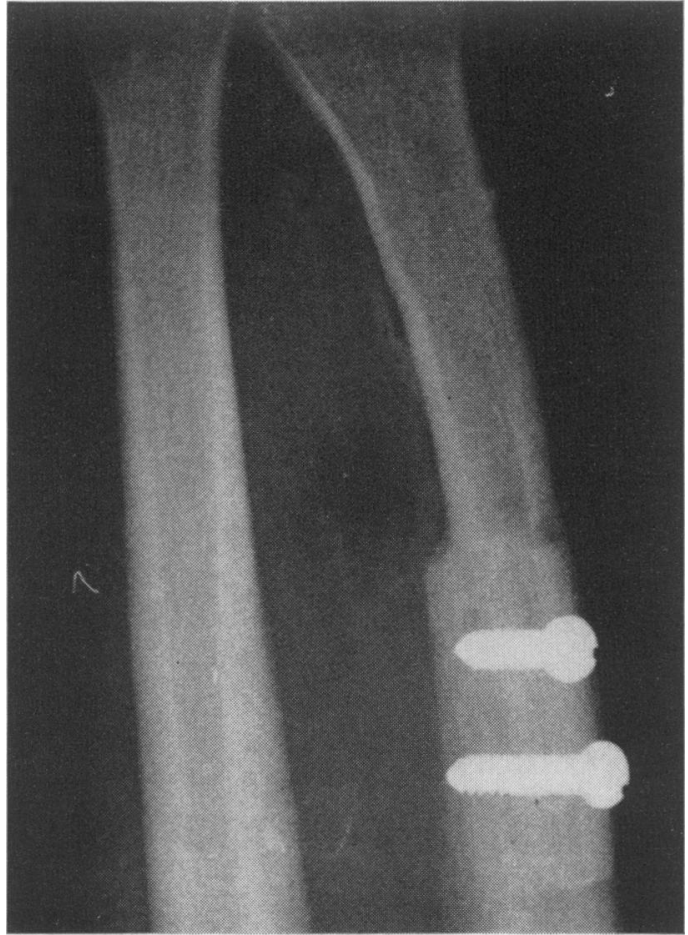

Fig. 3. Normal appearance of the fibular graft 3 months post-operatively, 8 January 1966.

radial deviation at the wrist had occurred, and X-ray showed displacement of the distal fragment (Fig. 6). The forearm was placed in a tight-fitting scaphoid plaster for 2 months. Subsequently this patient has been able to resume his employment as a landscape gardener, has a powerful grip, and gets pain only on wrenching of his wrist which has movements of: extension $25^{\circ}$, flexion $25^{\circ}$, rotation movement totalling $30^{\circ}$ and good abduction and adduction. :

\section{Discussion}

This patient has good function in a wrist following excision of the radius, with replacement by fan autogenous fibula graft from the opposite side, despite fracture and malunion of the graft. No change in the density or outline of the autograft in any of several X-rays taken during observation of his progress following the grafting procedure was demonstrable.

Approximately $10 \%$ of giant-cell tumours or bone are malignant at their onset, or become so during therapy. The longer the follow-up of these tumours, the higher the recurrence rate, and pulmonary metastases have been reported (Wilson \& Lance, 1965): radiation alone is not successful in controlling them and there is no evidence that it diminishes the rate of their recurrence (Johnson \& Dahlin, 


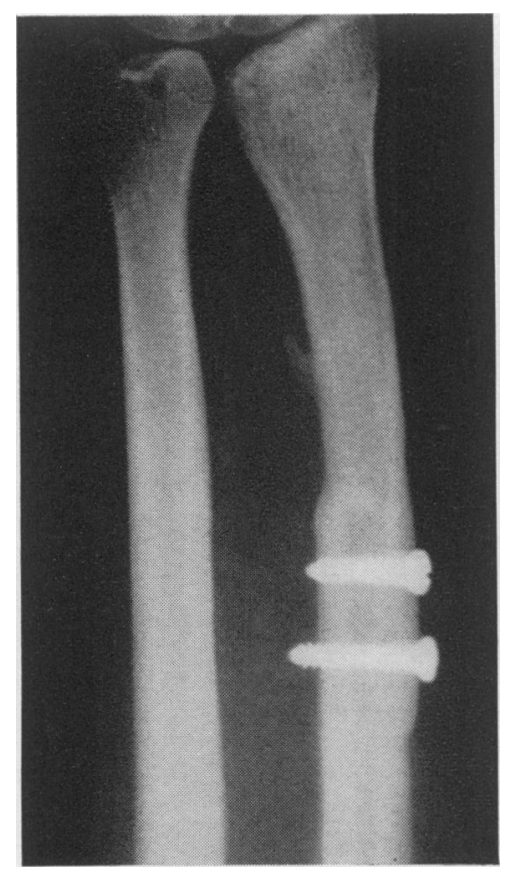

FIG. 4. No change in the radiographic outline or density of the fibular graft at 4 months, 12 February 1966.

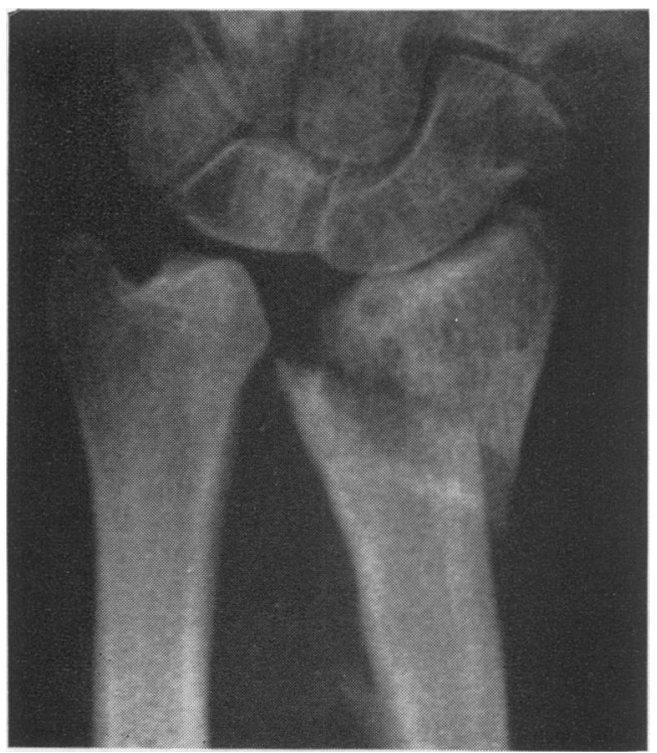

Fig. 5. Fracture through fibular graft after an injury playing soccer, 11 December 1966, 14 months after grafting.

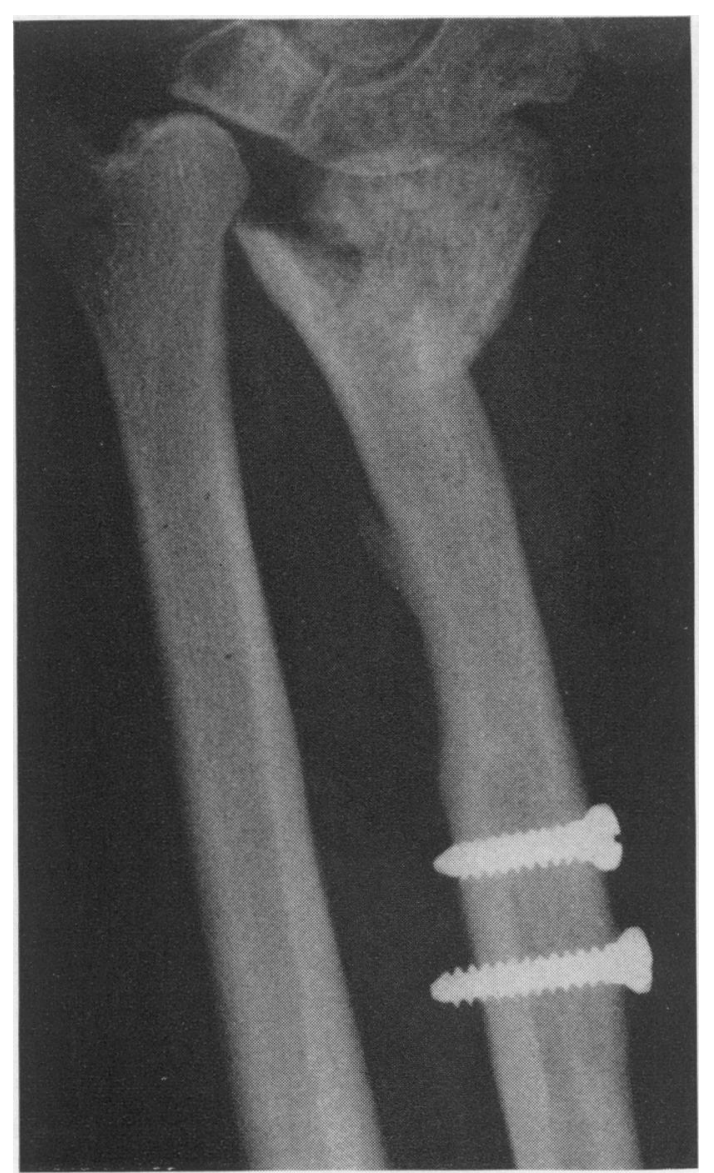

FIG. 6. Malalignment with minimal callus formation in fracture site, 13 March 1967, 3 months after fracture.

1959). Furthermore radiation may be influential in secondary sarcomatous change within these tumours.

Surgical extirpation of the affected bone where possible is the treatment of choice. Replacement of large bony defects by large autogenous grafts have been successful. An early half-joint replacement was performed by Tuffier in 1901, who replaced a femoral head following a fracture dislocation. Rovsing (1910) resected the proximal two-thirds of a humerus and replaced this with the proximal end of a fibula and stated that the patient had free passive movement 2 months post-operatively. A similar procedure was reported by Morrison (1914), but his case had nonunion of the graft with the humerus.

On examining the prints of X-rays following massive autogenous grafting, the grafts can be seen to become sclerotic after 3 weeks and following this, the edges are eroded and replaced by new bone, or merely enveloped in hypertrophied new bone formation. This was not seen to occur in this patient, the 
only erosion seen, followed a fracture, appearing as porosis around the fracture line. At operation the possibility of tumour recurrence or pathological fracture was excluded. A similar case reported by Lawson (1952) shows no alteration of the fibula graft outline post-operatively. Ross (1953) has followed the progress of a similar case for 15 years. There has been no change in the outline and density of the fibular implant apart from grooving of the articular end of the graft by the carpal bones and some sclerosis at 9 years. He has another patient with a 5-year post-operative follow-up in whom the radiological appearances have remained unchanged.

The fibula grafts used by Wilson \& Lance (1965) for humeral and femoral replacement show sclerosis, resorption and in one instance, a fracture. Their paper presented five cases of resection of the distal radius, with autogenous bone replacement from the iliac crest, resulting in cure with good function in two. They reported recurrence of giant-cell tumour within a graft, and also a lung metastasis. The fibula graft for resected tibial diaphysis for sarcoma by Gentil (1950), showed no graft change apart from hypertrophy with satisfactory function. Similarly the fibular replacement grafts used by Stewart \& Richardson (1952) have a normal appearance in density and outline in two of the three cases. In his paper of eleven cases of autograft transplants with attempt to allow epiphyseal growth to continue, Wilson (1966) shows reprints of radiographs in two cases where transplants of short tubular bone to the proximal phalanx of a toe and a finger, resulted in the growth of the epiphyseal plate in one instance. Both these transplants apparently maintained normal radiological density and contour. Key (1949) reported the survival and normal growth of a radial head after it had been removed and replaced during an operation for fractured neck of radius.

This maintenance of normal radiological outline and density is not a common feature of autogenous bone grafting. The reproductions of $\mathrm{X}$-rays, where fibular grafts were used in conjunction with SmithPetersen pins for fractured necks of the femur by Patrick (1949) show areas of sclerosis and resorption in the graft. Clark (1959) reported a 29-year follow-up on a patient who had an excision of the proximal end of the humerus for a giant-cell tumour in 1929, with satisfactory function of the limb. This graft had osteosclerotic and lytic areas. These changes are considered to be areas of graft death with replacement by host bone. Entin, Alger \& Baird (1962) when discussing the replacement of whole joints found that bone appeared to survive immediate transplantation, but remodelling commenced at 15 weeks with resorption and new bone formation which was usually completed at 35 weeks. They found there was survival of some of the cellular elements in bone. Stringa \& Mignani (1967), reporting their investigations of large autografts for bone defects, found that the autograft was dead. These patients did not have ideal conditions for graft survival in view of their age and pathological conditions. Here again the X-ray reproductions showed sclerosis and osteolytic areas within the grafts.

Where there is definite cell-death within the grafts, such as in cadaveric homografts when used as osteoarticular transplants (Ottolenghi, 1966), the grafts show increased radiographic density and margin outline changes while undergoing replacement. Thompson \& Streggal (1956) resected the proximal end of a femur for chondrosarcoma, curetted out the tumour, autoclaved the bone and returned it to its bed. At 2 weeks post-operatively there was no apparent change in the bone radiologically, but thereafter the changes of osteosclerosis and irregular margins were obvious.

Autogenous bone grafts of cancellous bone, or cortical grafts removed by osteotomy which necessitates hammering along their entire length, show radiological changes. The massive autografts and homografts for pseudarthrosis of the tibia (Boyd \& Fox, 1948) showed increased density on X-rays, as do the autografts by McFarland (1951) in the satisfactory X-ray reproductions of his article. The cancellous grafts of Nicoll (1956) have similar changes. Repair of femoral defects by massive tibial autografts by Phemister (1945) show sclerosis of the tibial replacements, followed by hypertrophy, with similar changes being seen in the reproductions of autografts used by Abbott et al. (1947).

This patient showed no radiological changes in bone density or outline until he sustained his fracture following football. Osteoporosis around the fracture line (Fig. 5), and subsequent X-rays, while showing no further change, also reveal very little new callus formation. He will still have to be watched for recurrence of tumour within the graft (Windeyer \& Woodyatt, 1949; Johnson \& Dahlin, 1959; Wilson \& Lance, 1965), but has satisfactory function and is able to follow the reasonably heavy occupation of landscape gardening.

It is realized that there must be considerable change in a graft to reveal radiological changes, and that increased density or osteoporosis is only apparent on X-ray some weeks following the grafting of known non-viable bone; nevertheless it is interesting that sometimes in grafts which have been dissected sub-periosteally without the use of hammering or a mechanical saw with the induction of heat, there is no apparent change, together with a rapid return of function.

The statement is maintained by some, that cells of autogenous bone grafts must die, but there are many authors who claim otherwise: and a study of 
TABLE 1

\begin{tabular}{llll}
\hline Trueta & $(1966)$ & Vainio \& Solonen & $(1957)$ \\
Puranen & $(1966)$ & Fell & $(1956)$ \\
Deleu \& Trueta & $(1965)$ & Maatz et al. & $(1954)$ \\
Arora \& Laskin & $(1964)$ & Campbell et al. & $(1953)$ \\
Burwell & $(1964)$ & Ray & $(1953)$ \\
Ray \& Sabet & $(1963)$ & Ham \& Gordon & $(1952)$ \\
Henja \& Ray & $(1963)$ & Reynolds, Oliver \& & \\
Enneking & $(1963)$ & Ramsey & $(1951)$ \\
White & $(1962)$ & Vainio & $(1950)$ \\
Goldhaber & $(1962 \mathrm{a}$, b) & Abbott et al. & $(1947)$ \\
Entin et al. & $(1962)$ & Phemister & $(1947)$ \\
Anderson & $(1961)$ & Albee & $(1944)$ \\
Ray \& Holloway & $(1957)$ & Gallie \& Robertson & $(1919)$ \\
Holmstrand & $(1957)$ & Dobrowolskaja & $(1917)$ \\
Vainio & $(1957)$ & Phemister & $(1914)$ \\
\hline
\end{tabular}

the articles by the authors in Table 1 presents a strong argument in favour of the latter. The percentage of survival, and the actual function in subsequent metabolism with destruction and reparation of the grafts is not known. The experiments of Puranen (1966) show that the role played by surviving cellular elements in grafts gently handled and transferred immediately from origin to insertion, can be appreciable. Fractures of autografts are known to heal, as seen in this patient, in experiences with grafts used in Brittain's arthodesis of the hip and in those shown by Phemister (1945). Anderson et al. (1964) state that this type of healing may be osteogenic induction of the surrounding connective tissues; but it could equally be due to living graft cells, or those of the new bone within the graft. It does appear from the examination of articles within Table 1, and the experience of most orthopaedic surgeons, that autogenous bone grafts are far superior to homogeneous or heterogeneous grafts, and those experiments or clinical findings where the latter preserved graft-types do well have probably in fact been of a composite graft-type, where the autogenous bone chips from the bony bed of the graft have been mixed with the homogeneous or heterogeneous bone. Sections examined in experimental studies of autogenous bone show cell death in the main, as these are small fragments and are near the site of excision with its accompanying trauma in most cases. Cellular survival with the possible end-to-end anastomosis of host bed vessels with those of the graft may account for more anabolic and metabolic function in a graft than has been appreciated in the past, especially in the cases where there has been gentle sub-periosteal dissection, immediate embedding in a vascular bed and adequate post-operative immobilization.

\section{References}

Abbott, L.C., Schottstaedt, E.R., Saunders, J.B.DeC. \& Bost, F.C. (1947) The evaluation of cortical and cancellous bone as grafting material. J. Bone Jt Surg. 29, 381.
Albee, F.H. (1944) Evolution of bone graft surgery. Amer. J. Surg. 63, 421.

ANDERSON, K.J. (1961) The behaviour of autogenous and homogeneous bone transplants in the anterior chamber of the rat's eye. J. Bone Jt Surg. 43A, 980.

Anderson, K.J., le CocQ, J.F., Akeson, W.H. \& HarringTON, P.R. (1964) End-point results of processed heterogeneous autogenous and homogeneous bone transplants in the human: histologic study. Clin. Orthop. 33, 220.

ARoRA, B.K. \& LASKIN, D.M. (1964) Sex chromatin as a cellular label of osteogenesis by bone grafts. J. Bone $J t$ Surg. 46A, 1269.

BoyD, H.B. \& Fox, K.W. (1948) Congenital pseudarthrosis. J. Bone Jt Surg. 30A, 274.

Burwell, R.G. (1964) Modern Trends in Orthopaedics (Ed. by M. P. Clark), Vol. 4, p. 138. Butterworths, London.

Campbell, C.J., Brower, T., Macfadden, D.G., Payne, E.B. \& Doherty, J. (1953) Experimental study of the fate of bone grafts. J. Bone Jt Surg. 35A, 332.

Clark, K. (1959) Case of replacement of upper end of humerus by fibular graft reviewed after twenty-nine years. J. Bone Jt Surg. 41B, 365.

Deleu, J. \& Trueta, J. (1965) Vascularisation of bone grafts in the anterior chamber of the eye. J. Bone Jt Surg. 47B, 319.

Dobrowolskaja, N.A. (1917) On the regeneration of bone in its relation to the cultivation of bone tissue. Brit. J. Surg. 4, 332.

ENNEKING, W.F. (1963) Immunological aspects of bone transplantation. J. Bone Jt Surg. 45A, 437.

Entin, M.A., Alger, J.R. \& Baird, R.M. (1962) Experimental and clinical transplantation of autogenous whole joints. J. Bone Jt. Surg. 44A, 1518.

Fell H.B. (1956) Biochemistry and Physiology of Bone (Ed. by G. H. Bourne), Chapter 14. Academic Press, New York.

Gallie, W.E. \& Robertson, D.E. (1919) The repair of bone. Brit. J. Surg. 7, 211.

Gentil, F. (1950) Excision of the shaft of the tibia for sarcoma. J. Bone Jt Surg. 32B, 389.

Goldhaber, P. (1962a) Some current concepts of bone physiology. New Engl. J. Med. 266, 924.

GolDHABER, P. (1962b) Calcification within diffusion chambers containing bone isografts. Clin. Orthop. 25, 1204.

HAM, A.W. \& Gordon, S. (1952) The origin of bone that forms in association with cancellous chips transplanted into muscle. Brit. J. plast. Surg. 5, 154.

HejnA, W.F. \& RAY, R.D. (1963) Comparative study of bone implants. Surg. Forum, 14, 448.

Holmstrand, K. (1957) Biophysical investigations of bone transplants and bone implants. Acta orthop. scand. Suppl. 26.

Johnson, E.W. \& Dahlin, D.C. (1959) Treatment of giant cell tumour of bone. J. Bone Jt Surg. 41A, 895.

KEY, J.A. (1949) Survival and growth of an epiphysis after removal and replacement. J. Bone Jt Surg. 31A, 150.

LAwSON, T.L. (1952) Fibular transplant for osteoclastoma of the radius. J. Bone Jt Surg. 34B, 74.

McFarland, B. (1951) Pseudarthrosis of the tibia in childhood. J. Bone Jt Surg. 33B, 36.

Morrison, R. (1914) Bone grafting in the arm. Brit. J. Surg. $1,383$.

Nicoll, E.A. (1956) The treatment of gaps in long bones by cancellous insert grafts. J. Bone Jt Surg. 38B, 70.

OtTolenghI, C.E. (1966) Massive osteoarticular bone grafts. J. Bone Jt Surg. 48A, 646.

PATrick, J. (1949) Intracapsular fractures of the femur treated with a combined Smith-Petersen nail and fibular graft. J. Bone Jt Surg. 31A, 67.

Phemister, D.B. (1914) The fate of transplanted bone and regenerative power of its various constituents. Surg. Gynec. Obstet. 19, 303. 
Phemister, D.B. (1945) Rapid repair of defect of femur by massive bone grafts after resection for tumours. Surg. Gynec. Obstet. 80, 120.

Phemister, D.B. (1947) Treatment of ununited fractures by onlay bone grafts without screw or tie fixation and without breaking down of the fibrous union. J. Bone Jt Surg. 29A, 946.

PuRANEN, J. (1966) Reorganisation of fresh and preserved bone transplants. Acta orthop. scand. Suppl. 92.

RAY, R.D. (1953) Discussion on the fate of bone grafts. J. Bone Jt Surg. 35A, 343.

RaY, R.D. \& Holloway, J.A. (1957) Bone implants. Preliminary report of an experimental study. J. Bone Jt Surg. 39A, 1119.

RAY, R.D. \& SABET, T.Y. (1963) Bone grafts: cellular survival versus induction. J. Bone Jt Surg. 45A, 337.

Reynolds, F.C., Oliver, D.R. \& Ramsey, R. (1951) Clinical evaluation of the merthiolate bone bank and homogeneous bone grafts. J. Bone Jt Surg. 33A, 873.

Ross, W.T. (1953) Osteoclastoma of radius. J. Bone Jt Surg. 35B, 326.

RovsiNG, T. (1910) Ein fall von freier knochentransplantation zum ersatz der zwei oberen drittel des oberarmes mit hilfe der fibula des patienten. Zbl. Chir. 37, 870.

Stewart, M.J. \& Richardson, T.R. (1952) Giant-cell tumour of bone. J. Bone Jt Surg. 34A, 372.
Stringa, G. \& Mignani, G. (1967) Microradiographic investigation of bone grafts in man. Acta orthop. scand. Suppl. 99.

Thompson, V.P. \& STegall, C.T. (1956) Chondrosarcoma of the proximal portion of the femur treated by resection and bone replacement. J. Bone Jt Surg. 38A, 357.

TruetA, J. (1966) Osteogenesis: studies since Macewen's time. Scot. med. J. 11, 33.

VAINIO, S. (1950) Observations on the regeneration of an autogenous transplant of the bone. Acta orthop. scand. $100,86$.

VAINIO, S. (1957) Transplantation of bone. Ann. chir. gynec. Fenn. Suppl. 67.

VAINIO, S. \& Solonen, K. (1957) The regenerative ability of the autoplastic and deep-frozen homoplastic transplant of bone. Ann. chir. gynec. Fenn. 46, 222.

White, R.G. (1962) Studies in transplantation of bone: a new approach. J. Bone Jt Surg. 44B, 3.

Wilson, J.N. (1966) Epiphyseal transplantation. J. Bone $J t$ Surg. 48A, 245.

Wilson, P.D. \& LANCE, E.M. (1965) Surgical reconstruction of the skeleton following segmental resection for bone tumours. J. Bone Jt Surg. 47A, 1629.

Windeyer, B.W. \& WoodyatT, P.B. (1949) Osteoclastoma. J. Bone Jt Surg. 31B, 225. 